\title{
Effects of Short-Term Treatment with Estrogen Receptor Agonist on Morphological Changes in Reproductive Organs of Adult Male Mice
}

\author{
Hayana Choi, Yun Jeong Mo, Mi-Kyung Lee ${ }^{1}$, Eun Sang Choe ${ }^{2}$, Sung Tae Yee ${ }^{3}$, Hyun Wook Cho* \\ Department of Biology, College of Life Science and Natural Resources, Sunchon National University, Suncheon 57922, Korea \\ ${ }^{1}$ Department of Food and Nutrition, College of Life Science and Natural Resources, Sunchon National University, \\ Suncheon 57922, Korea \\ ${ }^{2}$ Department of Biology, College of Natural Sciences, Pusan National University, Busan 46241, Korea \\ ${ }^{3}$ Department of Pharmacy, Sunchon National University, Suncheon 57922, Korea
}

*Correspondence to:

Cho HW,

Tel: +82-61-750-3614

Fax: $+82-61-750-3208$

E-mail: hwcho@sunchon.ac.kr

Received November 2, 2016

Revised December 19, 2016

Accepted December 20, 2016
Male reproductive organs are strongly affected by estrogen signaling mediated via the estrogen receptor. In this study, propyl pyrazole triol (PPT), an estrogen receptor alpha agonist, was subcutaneously injected in adult male mice every 2 days for a total duration of 8,16 , or 24 days. Histological changes in the reproductive organs, including the testes, efferent ductules, and epididymides, were observed. The weight of the reproductive organs decreased in the PPT group. In addition, the diameter of the seminiferous tubules decreased in the PPT group compared with the control group. The epithelial cell height decreased in the initial segment of the epididymis, whereas the luminal diameter increased in the efferent ductules of the PPT group. PPT induced irregular morphology of stereocilia in the luminal region of the initial segment. Therefore, PPT treatment at high concentrations had inhibitory effects in the reproductive organs of adult male mice. These findings suggest that short-term treatment with estrogen receptor agonist causes histological changes in the testes, efferent ductules, and epididymis, which are similar to those caused by estrogen receptor antagonist treatment. Therefore, the estrogen receptor may have functional roles in male reproductive organs, implying that treatment with an estrogen receptor agonist can affect male fertility.

Key Words: Estrogen receptor agonist, Propyl pyrazole triol, Male reproductive organ

\section{INTRODUCTION}

It is well established that estrogen and its receptors are localized to specific organs, including reproductive tissues of male animals (Carreau et al., 2007; Hess et al., 1997; Nie et al., 2002; O'Donnell et al., 2001; Oliveira et al., 2004; Yamashita, 2004; Zhou et al., 2002). Estrogen is activated via its receptors, estrogen receptor alpha (ER $\alpha$ or ESR1) and beta (ER $\beta$ or ESR2). The distribution and functions of ER $\alpha$ have been compared with those of ER $\beta$ in animals (Couse \& Korach, 1999; O'Donnell et al., 2001). ER is particularly localized to the efferent ductules, which connect the testis and epididymis (Fisher et al., 1997; Hess et al., 1997). Estrogen regulates the reabsorption of testis fluid in the efferent ductules via the interaction with ER $\alpha$, but the function of ER $\beta$ is not well known (Ford et al., 2014; Hess, 2003). ICI 182,780 (ICI) is a well- established ER antagonist (Cho et al., 2003; Oliveira et al., 2002, 2003), whereas propyl pyrazole triol (PPT) is an $\mathrm{ER} \alpha$ - specific agonist. The affinity of PPT for ER $\alpha$ has been reported to be at least 410 to 1,000 times higher compared with ER $\beta$ (Harris et al., 2002; Stauffer et al., 2000; Sun et al., 2002). ICI and PPT have been used for investigating estrogen

(a) This is an open-access article distributed under the terms of the Creative Commons Attribution Non-Commercial License (http://creativecommons.org/licenses/by-nc/4.0) which permits unrestricted noncommercial use, distribution, and reproduction in any medium, provided the original work is properly cited.

Copyrights @ 2016 by Korean Society of Microscopy 
function in male reproductive organs. Long-term treatment with PPT decreases the weights of the testis and epididymis, diameter of the seminiferous tubules, and epithelial cell height in the epididymis (Lee \& Cho, 2009). PPT also causes spermatogenesis disruption and infertility 8 weeks after treatment. This study aimed to identify histological changes in reproductive organs caused by short-term treatment with PPT compared with long-term treatment.

\section{MATERIALS AND METHODS}

\section{Animals and Treatment}

Thirty C57BL/6 male mice (10-week-old) were maintained under controlled conditions $\left(22^{\circ} \mathrm{C} \pm 2^{\circ} \mathrm{C}\right.$ at $50 \% \pm 5 \%$ relative humidity) and used for this study. The animals were randomly divided into two groups: control and PPT (4,4',4"(4-propyl-[1H]-pyrazole-1,3,5-triyl)tris-phenol; Tocris Cookson Ltd., United Kingdom). In the control group, the mice $(n=15)$ were subcutaneously injected every 2 days with $0.1 \mathrm{ml}$ of castor oil for 8,16 , or 24 days. In the PPT group animals, the mice $(n=15)$ were subcutaneously injected with $4 \mathrm{mg}$ PPT (PPT concentration per g body weight is 0.16 $\mathrm{mg}$ ) in $0.1 \mathrm{~mL}$ of castor oil every 2 days for 8,16 , or 24 days. In this study, the PPT concentration used was based on a previous method (Choi et al., 2013; Frasor et al., 2003; Lee \& Cho, 2009). Animals received commercial food and distilled water ad libitum. Animal experiments were performed with the approval (SCNU IACUC-2013-12) from the Sunchon National University Animal Care and Use Committee.

\section{Histological Preparation}

The control and PPT-treated mice were intraperitoneally anesthetized with sodium pentobarbital ( $50 \mathrm{mg} / \mathrm{kg}$ body weight), weighed, and intracardially perfused with $4 \%$ glutaraldehyde in $0.1 \mathrm{M}$ cacodylate buffer ( $\mathrm{pH} 7.4$ ) for 20 min. Animals were euthanized at specified time points 8 , 16, or 24 days post-treatment. The testis, efferent ductule, and epididymis were removed, and immersed in the same perfusion solution for further histological processing. For post-fixation, fat tissues attached to each organ were carefully detached. Organs were dried on filter papers prior to recording organ weights. For microscopy, the testis was cross-sectioned at the rete testis region, after which the tissue was dehydrated, embedded in glycol methacrylate resin, and sectioned into $2.5-\mu \mathrm{m}$ thick sections. The distal regions of the efferent ductules and epididymides were processed the same way as the testes. Sections were mounted on a glass slide and stained with periodic acid Schiff (PAS)-hematoxylin solution.

\section{Morphological Analysis}

Stained sections were pictured using a SPOT digital camera (Model No. 11.2 Color Mosaic; Diagnostic Instruments, USA) and morphometrically analyzed using the SPOT INSIGHT ${ }^{\mathrm{TM}}$ software (ver. 4.0; Diagnostic Instruments). Diameters of $8 \sim 10$ seminiferous tubules of stages VII or VIII per testis were measured on the basis of smallest cross-sectional diameter. Luminal diameters of 10 sites in the distal efferent ductules of each mouse were determined by measuring the widest diameter in the cross-section. Cell heights from the basement membrane to the microvillus tip of 30 non-ciliated epithelial cells per mouse were measured in straight sections of the distal efferent ductules. The cilia length was determined by measurement from the free surface of the epithelim to the cilia tip in 10 ciliated cells in the efferent ductules. Cell heights and streocilia lengths were also determined for 30 and 10 principal cells in the initial segment of the epididymis, respectively.
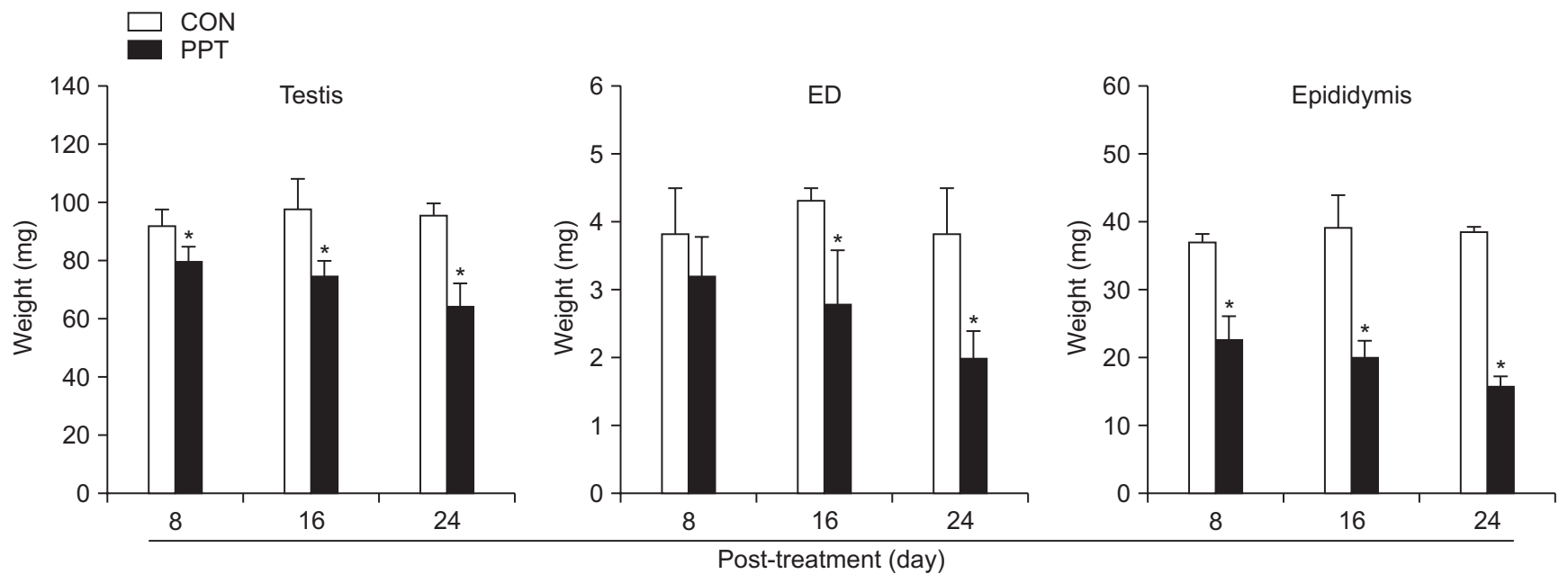

Fig. 1. Weights of reproductive organs from the control (CON) and propyl pyrazole triol (PPT) groups at 8, 16 and 24 days post-treatment. Weights of the testes, efferent ductules (EDs), and epididymides were decreased because of PPT treatment. Significant differences $(*)$ between the control and PPT groups were observed $(\mathrm{p}<0.05)$. Data indicate mean \pm standard deviation. 


\section{Statistical Analysis}

Statistical differences between the control and PPT groups were analyzed using one-way ANOVA with the Microsoft Office Excel. A p-value of $<0.05$ was considered to be significantly different.

\section{RESULTS}

PPT administration decreased reproductive organ weights in the PPT group (Fig. 1). In the first sacrificed mice of the PPT group, organ weights were significantly decreased at 24 days post-treatment compared with 8 days post-treatment. At 24 days post-treatment the weights of the epididymides were decreased (58.1\%) in the PPT group compared with those in the control group.

\section{Testis}

In both the control and PPT groups, developing sperm heads were observed in the seminiferous tubules of the testes. In the PPT group, the diameters of the seminiferous tubules gradually decreased at each experimental time point (Fig. 2).

\section{Efferent Ductules}

Efferent ductules are composed of proximal, conus, and distal regions. In the control group, the luminal diameters of the distal region of the efferent ductules were 29.6, 32.3, and $58.6 \mu \mathrm{m}$ at 8,16 , and 24 days post-treatment, respectively. In contrast, in the PPT group, the diameters were 36.7, 48.0, and $86.1 \mu \mathrm{m}$, respectively (Table 1). The diameters of the efferent ductules significantly increased in the PPT group compared with the control group (Fig. 3). Epithelial cell heights were decreased by $7.2 \%, 9.4 \%$, and $7.8 \%$ at 8,16 , and 24 days posttreatment, respectively, in the PPT group compared with the control group. Cilia length of ciliated cells appeared to be longer in the PPT group (23.5\% increase at 8 days posttreatment) than in the control group however, appeared to be shorter at 16 and 24 days post-treatment (Table 2).

\section{Epididymis}

The initial segment of the epididymis is connected to the
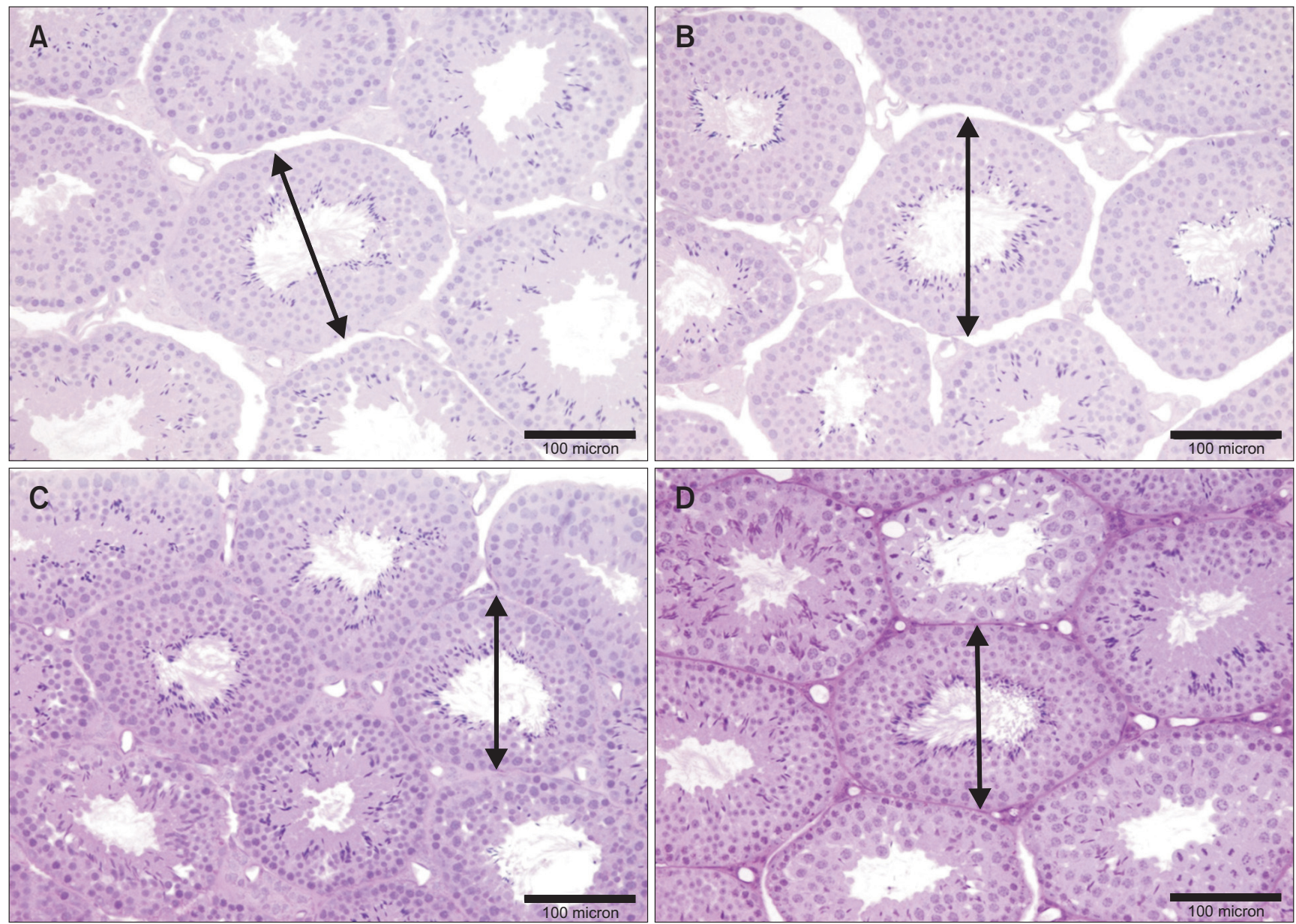

Fig. 2. Photomicrographs of testes from the (A) control at 8 days and propyl pyrazole triol groups at (B) 8 , (C) 16 , and (D) 24 days post-treatment. Double arrows indicate seminiferous tubular diameter. Bar size $=100 \mu \mathrm{m}$. 


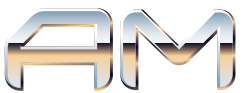

Choi H et al.

Table 1. Several parameters of reproductive organs in control and PPT groups

\begin{tabular}{|c|c|c|c|c|}
\hline \multirow{2}{*}{ Parameter $(\mu \mathrm{m})$} & \multirow{2}{*}{ Group } & \multicolumn{3}{|c|}{ Post-treatment (day) } \\
\hline & & 8 & 16 & 24 \\
\hline \multirow[t]{3}{*}{ Seminiferous tubular diameter in testis } & Control & $201.4 \pm 18.5$ & $198.6 \pm 15.1$ & $211.5 \pm 17.6$ \\
\hline & PPT & $196.1 \pm 18.4^{*}$ & $182.9 \pm 18.2^{*}$ & $177.7 \pm 19.9^{*}$ \\
\hline & Rate & $2.6 \% \downarrow$ & $7.9 \% \downarrow$ & $15.9 \% \downarrow$ \\
\hline \multirow[t]{3}{*}{ Epithelial cell height in efferent ductules } & Control & $22.2 \pm 2.8$ & $20.2 \pm 2.6$ & $15.3 \pm 2.3$ \\
\hline & PPT & $20.6 \pm 2.8^{*}$ & $18.3 \pm 2.4^{*}$ & $14.1 \pm 2.1^{*}$ \\
\hline & Rate & $7.2 \% \downarrow$ & $9.4 \% \downarrow$ & $7.8 \% \downarrow$ \\
\hline \multirow{3}{*}{ Luminal diameter in efferent ductules } & Control & $29.6 \pm 14.7$ & $32.3 \pm 11.5$ & $58.6 \pm 16.1$ \\
\hline & PPT & $36.7 \pm 12.7^{*}$ & $48.0 \pm 13.6^{*}$ & $86.1 \pm 18.9 *$ \\
\hline & Rate & $23.9 \% \uparrow$ & $48.6 \% \uparrow$ & $46.9 \% \uparrow$ \\
\hline \multirow[t]{3}{*}{ Epithelial cell height in initial segment of epididymis } & Control & $60.7 \pm 7.4$ & $53.0 \pm 8.2$ & $51.1 \pm 6.7$ \\
\hline & PPT & $39.1 \pm 6.7^{*}$ & $34.3 \pm 5.1^{*}$ & $27.5 \pm 4.3^{*}$ \\
\hline & Rate & $35.5 \% \downarrow$ & $35.2 \% \downarrow$ & $46.1 \% \downarrow$ \\
\hline
\end{tabular}

Values are presented as mean \pm standard deviation.

PPT, propyl pyrazole triol; $\downarrow$, decrease; $\uparrow$, increase.

${ }^{*} \mathrm{p}<0.05$ compared with control group.
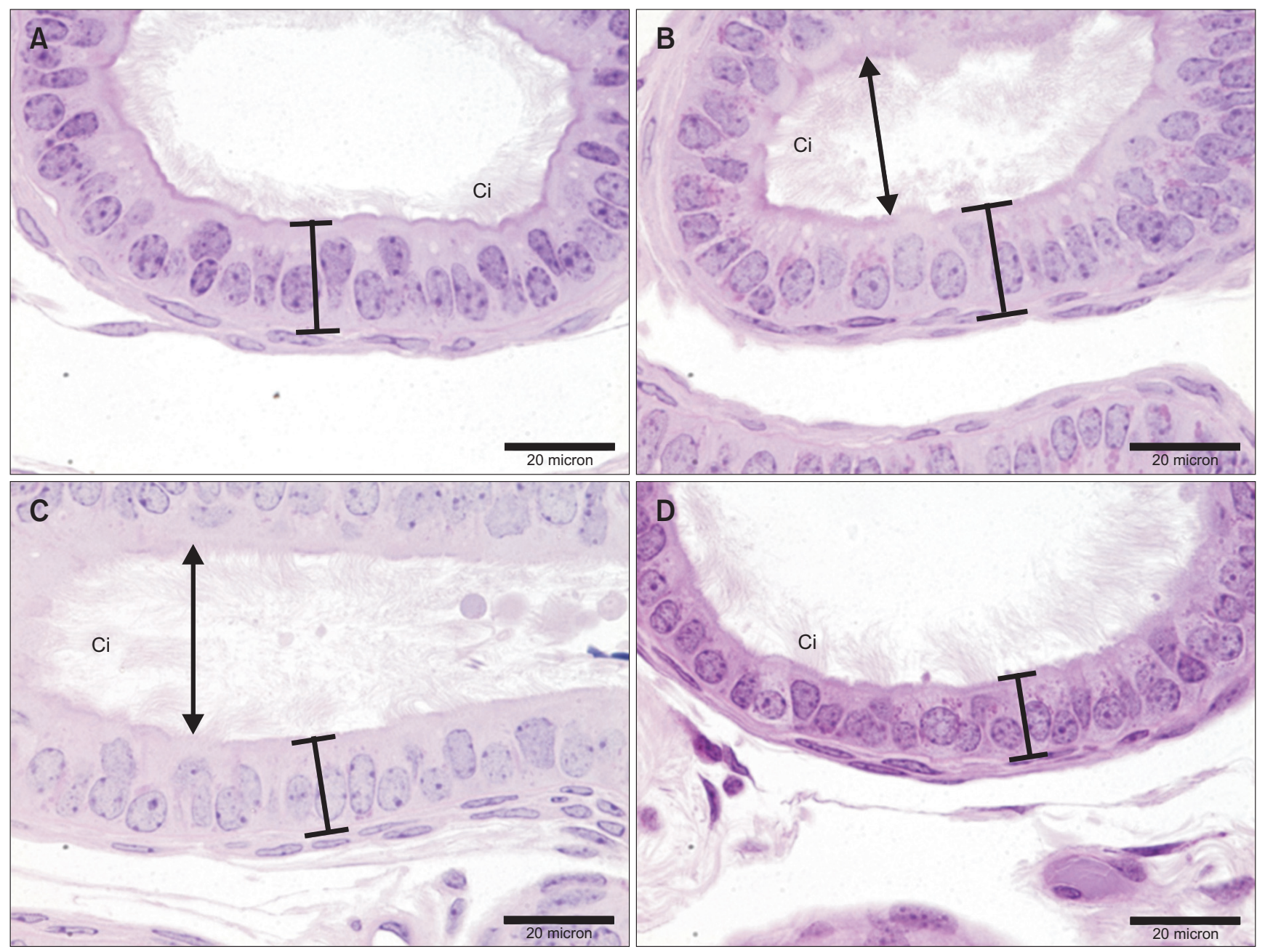

Fig. 3. Photomicrographs of efferent ductules from the (A) control at 8 days and propyl pyrazole triol groups at (B) 8, (C) 16 , and (D) 24 days post-treatment. Cilia $(\mathrm{Ci})$ of ciliated cells appeared in the lumen of the efferent ductules. Black lines indicate epithelial cell height. Double arrows indicate the luminal diameter of the efferent ductule. Bar size $=20 \mu \mathrm{m}$. 
efferent ductules and showed altered epithelial cell height and PAS staining intensity. Cell heights of the initial segment were $35.5 \%, 35.2 \%$, and $46.1 \%$ shorter at 8,16 , and 24 days post-treatment, respectively in the PPT group than in the control group (Fig. 4). PAS staining intensity of the cytoplasm of principal cells (or epithelial cells) surrounding the lumen was stronger in the PPT group than in the control group, depending on the time point being investigated. Stereocilia of

Table 2. Cilia and stereocilia lengths in the efferent ductules and in the initial segment of epididymis, respectively

\begin{tabular}{|c|c|c|c|c|}
\hline \multirow{2}{*}{ Length $(\mu \mathrm{m})$} & \multirow{2}{*}{ Group } & \multicolumn{3}{|c|}{ Post-treatment (day) } \\
\hline & & 8 & 16 & 24 \\
\hline \multirow[t]{3}{*}{ Cilia length of ciliated cells in the efferent ductules } & Control & $8.5 \pm 1.3$ & $9.5 \pm 1.5$ & $10.5 \pm 1.5$ \\
\hline & PPT & $10.5 \pm 2.0^{*}$ & $8.5 \pm 1.6^{*}$ & $9.2 \pm 1.3^{*}$ \\
\hline & Rate & $23.5 \% \uparrow$ & $10.5 \% \downarrow$ & $12.4 \% \downarrow$ \\
\hline \multirow[t]{3}{*}{ Stereocilia length of principal cells in the initial segment } & Control & $14.1 \pm 2.0$ & $14.7 \pm 2.6$ & $17.4 \pm 3.4$ \\
\hline & PPT & $12.1 \pm 2.2^{*}$ & $11.4 \pm 2.1^{*}$ & $12.0 \pm 2.1^{*}$ \\
\hline & Rate & $14.2 \% \downarrow$ & $22.4 \% \downarrow$ & $31.0 \% \downarrow$ \\
\hline
\end{tabular}

Values are presented as mean \pm standard deviation.

PPT, propyl pyrazole triol; $\downarrow$, decrease; $\uparrow$, increase.

${ }^{*} \mathrm{p}<0.05$ compared with control group.
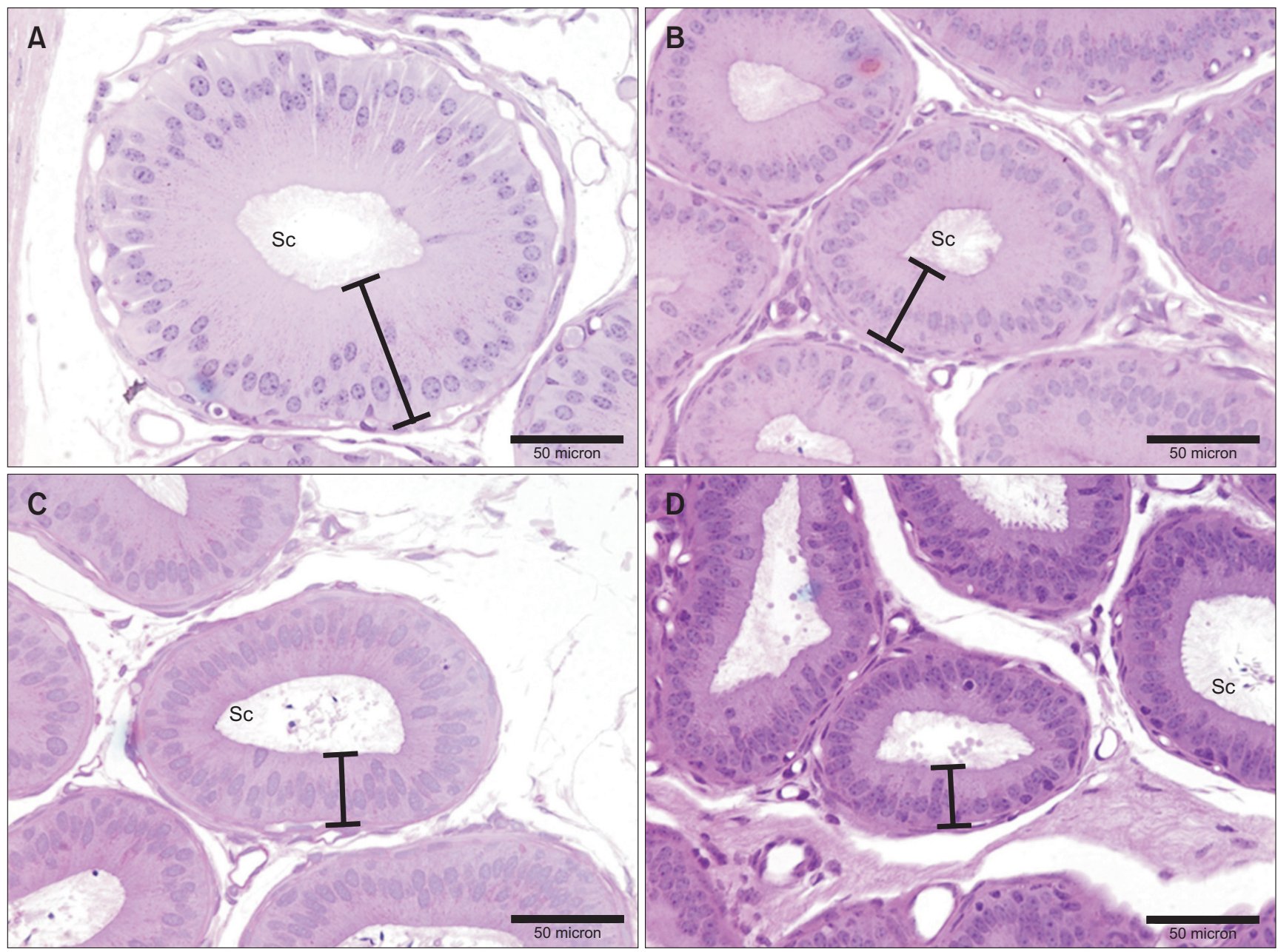

Fig. 4. Photomicrographs of the initial segment of the epididymides from the (A) control at 8 days and propyl pyrazole triol groups at (B) 8 , (C) 16 , and (D) 24 days post-treatment. Stereocilia (Sc) appeared in the lumen of the initial segment. Black lines indicate epithelial cell height. Bar size $=50 \mu \mathrm{m}$. 
principal cells showed a disorganized or scattered morphology in the luminal region of the PPT group. In the PPT group, stereocilia lengths were decreased by $14.2 \%, 22.4 \%$, and $31.0 \%$ compared with the control group at 8,16 , and 24 days post-treatment (Table 2).

\section{DISCUSSION}

This study revealed the histological changes in the testis, epididymis, and efferent ductule in mice treated with the ER agonist PPT for a short-term. Frasor et al. (2003) investigated immature female (21-day-old) mice subcutaneously injected daily with various PPT concentrations $(20,100$, and $500 \mu \mathrm{g} /$ animal/day) for 4 days. In their results, uterine weight or serum prolactin levels were most affected by $500 \mu \mathrm{g}$ PPT. Referencing these data, $4 \mathrm{mg}$ PPT was administered to adult mice every 2 days. In the PPT group, the weights of the testis, epididymis, and efferent ductule decreased, and the decrease was time- dependent. The weight of the testes decreased by $12.7 \%, 23.2 \%$, and $31.6 \%$ at 8,16 , and 24 days post-treatment, respectively. However, spermatogenesis continued through 24 days post-treatment. In a previous study, after administering $4 \mathrm{mg}$ PPT administration per week for 3, 5, and 8 weeks, the weight of the testes decreased by $24.5 \%, 46.2 \%$, and $79.5 \%$, respectively (Lee \& Cho, 2009); in addition, spermatogenesis did not occur in markedly atrophied seminiferous tubules by week 8 . Therefore, sperms did not accumulate in the caudal epididymis after 8 weeks of treatment. The weight of the testis was more strongly affected after long-term PPT treatment in the previous study (Lee \& Cho, 2009) than that after 16-day in the present study. Estrogens are correlated with histopathology, spermatogenesis regulation, and morphological changes in male reproductive organs (Aleem et al., 2006; Cho et al., 2003; Hess et al., 1997; Oliveira et al., 2003). Exposure to the synthetic hormone, 17 $\beta$-estradiol (E2), has been shown to induce Leydig cell atrophy, seminiferous tubule degeneration, and decreased sperm production, resulting in decreased testis weight (Cook et al., 1998). Estrogens are closely related to testicular development, spermatogenesis control, and male fertility (Carreau et al., 2007; Sinkevicius et al., 2009; Toyama et al., 2001). Estrogens also suppress c-KIT (type III receptor tyrosine kinase) expression in seminiferous tubules of the testis and simultaneously decrease proliferation and increase apoptosis in germ cells. Therefore, an increased estrogen concentration results in male infertility and c-KIT expression (Figueira et al., 2014). As described in the present study, decreased testis weight was correlated with atrophied seminiferous tubular diameter at high PPT concentrations. Higher doses of the synthetic estrogen, diethylstilbestrol (DES) have inhibitory effects in the testis, whereas lower doses of DES have a stimulatory effect in the same organ (Goyal et al., 2003). The stimulatory effect of low concentration DES treatment is because of the direct action of estrogen on Sertoli and/or germ cells.

Our results indicate the decrease of epithelial cell height and increase of luminal diameter in the efferent ductules of the PPT group. The ER antagonist ICI inhibits fluid reabsorption in the efferent ductules, resulting in a swollen luminal diameter and decreased epithelial cell height (Cho et al., 2003; Hess et al., 2011; Oliveira et al., 2003). In the present study, a high PPT concentration caused similar results as the ICI treatment in the efferent ductules. However, it remains to be elucidated whether PPT inhibits fluid reabsorption in the efferent ductules. Cilia length of ciliated cells in the efferent ductules increased in the PPT treatment at 8 days post-treatment. However, the cilia length was decreased at 16 and 24 days in the present study. These results may suggest that PPT had an agonistic (at earlier experiment time) and antagonistic (at late experiment time) effect on cilia.

PPT treatment dramatically decreased epithelial cell height in the initial segment of the epididymides. Cell heights specifically decreased by $35.5 \%, 35.2 \%$, and $46.1 \%$ at 8,16 , and 24 days post-treatment, respectively, in the PPT group compared with the control group. Stereocilia (long microvilli) were irregularly arranged, and immature cells appeared in the luminal region of the initial segment in the PPT group. Moreover, stereocilia of the initial segment appeared to be irregular and were short. These results suggest that the roles of stereocilia, such as fluid resorption, are affected by PPT treatment.

Epithelial cell heights were decreased by $46.1 \%, 49.9 \%$, and 63.0\% after PPT treatment for 3, 5, and 8 weeks, respectively, and stereocilia were disrupted after 8 weeks of long-term PPT treatment (Lee \& Cho, 2009). These results suggest that cellular morphology was more affected by longterm PPT treatment. Estrogens affect cellular morphology and microvillus length (Sapino et al., 1986; Wakeling et al., 1989). In the present study, a high PPT concentration decreased epithelial cell height or caused irregular stereocilia morphology in the initial segment of the epididymis.

Estrogen induces positive or negative effects on reproductive organs depending on its concentration. A high concentration (10 $\mu \mathrm{g} / \mathrm{rat} /$ day) of DES decreases testis weight, whereas a low concentration ( $1 \mathrm{ng} / \mathrm{rat} /$ day) increase testis weight in neonatal rats (Goyal et al., 2003). Reproductive organs are differentially affected by PPT depending on the concentration (Han et al., 2011). Tissue weights of organs were more strongly affected by a high PPT concentration $(4 \mathrm{mg}$ ) than a low concentration $(0.01 \mathrm{mg}, 0.1 \mathrm{mg}$, and $1.0 \mathrm{mg})$. In the present study, a high PPT concentration ( $4 \mathrm{mg} / \mathrm{mouse} / 2$ days) induced a negative reaction in the form of decreased epithelial cell height and enlarged luminal diameter in the efferent ductules, which is similar to ICI treatment. 


\section{CONCLUSIONS}

In the current study, short-term treatment with a high PPT concentration decreased the weights of reproductive organs, including the testis, epididymis, and efferent ductules; caused atrophy of seminiferous tubules; decreased epithelial cell height in the epididymis and efferent ductules; and enlarged luminal diameter in the efferent ductules. Compared with long-term treatment, histology of sex organs was less affected by short-term PPT treatment in the present study. These results suggest that a high PPT concertation induces an inhibitory effect in adult male reproductive organs.

\section{CONFLICT OF INTEREST}

No potential conflict of interest relevant to this article was reported.

\section{ACKNOWLEDGMENTS}

This study was supported by the Sunchon National University Research Fund in 2016. The authors thank Yu Seon Kim for technical assistance.

\section{REFERENCES}

Aleem M, Padwal V, Choudhari J, Balasinor N, Parte P, and Gill-Sharma M K (2006) Estradiol affects androgen-binding protein expression and fertilizing ability of spermatozoa in adult male rats. Mol. Cell. Endocrinol. 253, 1-13.

Carreau S, Silandre D, Bourguiba S, Hamden K, Said L, Lambard S, Galeraud-Denis I, and Delande C (2007) Estrogens and male reproduction: a new concept. Braz. J. Med. Biol. Res. 40, 761-768.

Cho H W, Nie R, Carnes K, Zhou Q, Sharief N A Q, and Hess R A (2003) The antiestrogen ICI 182,780 induces early effects on the adult male mouse reproductive tract and long-term decreased fertility without testicular atrophy. Reprod. Biol. Endocrinol. 1, 57.

Choi H, Seong C N, Park M S, and Cho H W (2013) Effects of alternate treatment of estrogen receptor antagonist and agonist on morphology of male reproductive organs of adult mice. Appl. Microsc. 43, 103-109.

Cook J C, Johnson L, O'Connor J C, Biegel L B, Krams C H, Frame S R, and Hurtt M E (1998) Effects of dietary 17 beta-estradiol exposure on serum hormone concentrations and testicular parameters in male Crl:CD BR rats. Toxicol. Sci. 44, 155-168.

Couse J F and Korach K S (1999) Estrogen receptor null mice: what have we learned and where will they lead us? Endocr. Rev. 20, 358-417.

Figueira M I, Cardoso H J, Correia S, Maia C J, and Socorro S (2014) Hormonal regulation of C-KIT receptor and its ligand: implications for human infertility? Prog. Histochem. Cytochem. 49, 1-19.

Fisher J S, Millar M R, Majdic G, Saunders P T, Fraser H M, and Sharpe R M (1997) Immunolocalisation of oestrogen receptor-alpha within the testis and excurrent ducts of the rat and marmoset monkey from perinatal life to adulthood. J. Endocrinol. 153, 485-495.

Ford Jr J, Carnes K, and Hess R A (2014) Ductuli efferentes of the male golden Syrian hamster reproductive tract. Andrology 2, 510-520.

Frasor J, Barnett D H, Danes J M, Hess R, Parlow A F, and Katzenellenbogen B S (2003) Response-specific and ligand dose-dependent modulation of estrogen receptor (ER) $\alpha$ activity by ER $\beta$ in the uterus. Endocrinology 144, 3159-3166.

Goyal H O, Robateau A, Braden T D, Williams C S, Srivastava K K, and Ali K (2003) Neonatal estrogen exposure of male rats alters reproductive functions at adulthood. Biol. Reprod. 68, 2081-2091.

Han J Y, Cho Y K, and Cho H W (2011) Concentration effect of estrogen receptor- $\alpha$ selective agonist on the morphology of reproductive organs of the male mice. Kor. J. Microsc. 41, 37-45.

Harris H A, Katzenellenbogen J A, and Katzenellenbogen B S (2002) Characterization of the biological roles of the estrogen receptors, $E R \alpha$ and $E R \beta$, in estrogen target tissues in vivo through the use of an ER $\alpha$-selective ligand. Endocrinology 143, 4172-4177.

Hess R A (2003) Estrogen in the adult male reproductive tract: a review. Reprod. Biol. Endocrinol. 1, 52.

Hess R A, Bunick D, Lee K H, Bahr J, Korach K S, and Lubahn D B (1997) A role for oestrogens in the male reproductive system. Nature $\mathbf{3 9 0}$, 509-512.

Hess R A, Fernandes S A F, Gomes G R O, Oliveira C A, Lazari M F M, and Porto C S (2011) Estrogen and its receptors in efferent ductules and epididymis. J. Androl. 32, 600-613.

Lee E J and Cho H W (2009) Estrogen receptor alpha agonist propyl pyrazole triol causes alterations of the morphology and function of the mouse male reproductive system. Anim. Cells Syst. 13, 205-212.

Nie R, Zhou Q, Jassim E, Saunders P T, and Hess R A (2002) Differential expression of estrogen receptors alpha and beta in the reproductive tracts of adult male dogs and cats. Biol. Reprod. 66, 1161-1168.

O'Donnell L, Robertson K M, Jones M E, and Simpson E R (2001) Estrogen and spermatogenesis. Endocr. Rev. 22, 289-318.

Oliveira C A, Mahecha G A B, Carnes K, Prins G S, Saunders P T K, Franca L R, and Hess R A (2004) Differential hormonal regulation of estrogen receptors ER $\alpha$ and ER $\beta$ and androgen receptor expression in rat efferent ductules. Reproduction 128, 73-86.

Oliveira C A, Nie R, Carnes K, Franca L R, Prins G S, Saunders P T K, and Hess R A (2003) The antiestrogen ICl 182,780 decreases the expression of estrogen receptor-alpha but has no effect on estrogen receptor-beta and androgen receptor in rat efferent ductules. Reprod. Biol. Endocrinol. 1, 75.

Oliveira C A, Zhou Q, Carnes K, Nie R, Kuehl D E, Jackson G L, Franca L R, Nakai M, and Hess R A (2002) ER function in the adult male rat: Short- and long- term effects of the antiestrogen ICI 182,780 on the testis and efferent ductules, without changes in testosterone. Endocrinology 143, 2399-2409.

Sapino A, Pietribiasi F, Bussolati G, and Marchisio P C (1986) Estrogenand tamoxifen-induced rearrangement of cytoskeletal and adhesion structures in breast cancer MCF-7 cells. Cancer Res. 46, 25262531. 
Sinkevicius K W, Laine M, Lotan T L, Woloszyn K, Richburg J H, and Greene G L (2009) Estrogen-dependent and -independent estrogen receptor- $\alpha$ signaling separately regulate male fertility. Endocrinology 150, 2898-2905.

Stauffer S R, Coletta C J, Tedesco R, Nishiguchi G, Carlson K, Sun J, Katzenellenbogen B S, and Katzenellenbogen J A (2000) Pyrazole ligands: Structure-affinity/activity relationships and estrogen receptor- $\alpha$-selective agonists. J. Med. Chem. 43, 4934-4947.

Sun J, Huang Y R, Harrington W R, Sheng S, Katzenellenbogen J A, and Katzenellenbogen B S (2002) Antagonists selective for estrogen receptor $\alpha$. Endocrinology 143, 941-947.

Toyama Y, Hosoi I, Ichikawa S, Maruoka M, Yashiro E, Ito H, and Yuasa S
(2001) $\beta$-estradiol 3-benzoate affects spermatogenesis in the adult mouse. Mol. Cell. Endocrinol. 178, 161-168.

Wakeling A E, Newboult E, and Peters S W (1989) Effects of antiestrogens on the proliferation of MCF-7 human breast cancer cells. J. Mol. Endocrinol. 2, 225-234.

Yamashita S (2004) Localization of estrogen and androgen receptors in male reproductive tissues of mice and rats. Anat. Rec. 279A, 768778.

Zhou Q, Nie R, Prins G S, Saunders P T K, Katzenellenbogen B S, and Hess R A (2002) Localization of androgen and estrogen receptors in adult male mouse reproductive tract. J. Androl. 23, 870-881. 